Muskhelishvili and his school "are not at all widely known". A survey of the research literature of the past twenty years indicates quite the contrary-engineers working on two-dimensional problems in the theory of elasticity seem to be perfectly well aware that this is one of the basic research tools of the subject and that they can find excellent accounts of it in the books of Muskhelishvili, Green and Zerna and Ghakov. Also, the account given in the present text (limited to five pages) is too brief and confused to be intelligible to a beginner.

Similarly, in introducing the contents of his chapter on integral transforms the author states that "it is very surprising to find that there is a dearth of literature on those aspects of the subject other than the Laplace and Fourier transforms", yet his references (10) and (12) are widely used by engineers and physicists and they contain considerably more, both of the theory and the applications. of Hankel and Mellin transforms which are here dealt with in six and three pages respectively. No mention is mado of other transforms which are widely used: those of Hilbert, Stieltjes, Kontorovich-Lebedev, Mehler-Fock, the $K$-transform, the $\mathbf{H}$-transform and the $Y$-transform.

What I find very surprising is that in a book on boundary value problems no mention is made of the Robin problem ("radiation" boundary conditions) or of mixed boundary value problems.

This book perpetuates the view held by most foreign mathematicians that in England the study of applied mathematics is reduced to training in solving examination-type problems; it has over a hundred problems each with a reference to the university examination paper from which it was taken. This method of acknowledging the source of problems grew up in the past century when examiners often published original results in the form of tripos questions. It is doubtful if there is any value in continuing it today unless an author is prepared to take a great deal of pains to acknowledge the original source. For example, problems (26) and (27) of exercise 7, dated by the author as 1964 and 1967 respectively, appeared as worked examples on pages $136-137$ of reference (10) which was published in 1951 .

Most publishers are keen to have a book on partial differential equations "on their list". What is so surprising about the decision of the publishers to accept the manuscript of this book is that in M. G. Smith's Introduction to the Theory of Partial Differential Equations, which they published as recently as 1967, they already had a much better book written for the same class of students as the present one. It is a modern introduction to the subject which is much to be preferred to the book under review,

I. $\Lambda^{r}$. SNEDDON

\section{ROCK ANALYSIS}

\section{Elemental Analysis in Geochemistry}

Part A: Major Elements. By Alexis Volborth. (Methods in Geochemistry and Geophysics, No. 8.) Pp. $x v+373$. (Elsevier: Amsterdam, London and New York, 1969.) $135 s$.

THIs book is presented as a manual of classical analysis of major elements for the instrumentalist and of physical analysis for the classical chemist and as a useful general addition to the library of experienced workers. To achieve this is a formidable task.

Half of the text is devoted to methods of classical gravimetric analysis, and is followed by chapters on emission flame spectrophotometry, atomic absorption and X-ray emission spectrometry and fast neutron activation analysis. After considering problems of sampling and preparation procedures, each element (many of which should be more appropriately considered as minor elements) is introduced at an unnecessarily elementary level. The author sometimes chooses complicated, although well founded, classical methode, and his instructions are usually difficult to follow. The inclusion of more alternative colorimetric methods, which have often the same reliability as gravimetric methods, would have helped the inexperienced analyst. Discussion on problems of element interferences, often neglected in other analytical works, is most welcome.

The chapter on atomic absorption spectrometry serves as a useful introduction, although it is doubtful if sufficient coverage is given to this and to methods of $\mathrm{X}$-ray emission analysis. The problems of $\mathrm{X}$-ray analysis are often oversimplified, especially on unfused rocks, and precision rather than accuracy is over-emphasized. No reference sources are supplied for matrix correction methods (for example, Norrish et al.) which involves about a quarter of this chapter. There is confusion about detection limit, precision and accuracy, which in one case (page 187) are used almost synonymously.

Although Professor Volborth is justly renowned for developing the technique of fast neutron activation analysis of rocks, this method is hardly relevant to the stated aim of the book, because at this stage of gerchemical analysis it is beyond the capabilities of most laboratories. Although there is an excellent index in the book (44 pages), the unfortunate lack of references to original sources of analytical methods places severe limits on its usefulness.

The element of artificiality in this whole series on "Methods in Geochemistry and Geophysics" is illustrated by the frequent discussion in the text of minor element analysis, although this will be covered in Part B of this volume, as well as in three other volumes. Volborth should be praised for recognizing the need for a manual combining both physical and classical methods. It would, however, have been perhaps more efficient, and certainly more economical, if the separate related books of the series were included in one volume. N. B. PRICE

\section{VIRUS-VECTOR RELATIONSHIPS}

\section{Viruses, Vectors and Vegetation}

Edited by Karl Maramorosch. Pp. xï +666. (Interscience (Wiley): New York and London, July 1969.) $281 s$.

ThIRTY-ThReE contributors have provided twenty-nine papers for this book, and the different styles, methods of presentation and occasional abrupt change of topic inevitably make for difficult reading. The editor has rightly put first the stimulating paper by Oman on the criteria of specificity in virus-vector relationships. This paper emphasizes once again the need for a greater knowledge of the physiology and biochemistry of insect vectors and yet one sees so little evidence of this demand boing satisfied.

The several classes of vectors of plant viruses are well reported as are the various mechanisms of infection involved. Particular mention can be made of the thoughtful treatment by Teakle of fungal vectors and this could encourage others to take on this interesting topic. Taylor and Cadman have produced a clear statement of the complicated virus-nematode association and this should help to resolve the often confused ideas that circulate. The paper by Forbes and MacCarthy on the morphology of the Homoptera is a welcome addition, not only because such information is scattered in the literature but because an understanding of the basic structure of the vector is a key point in the interpretation of virus-vector relationships.

Fukushi has provided a faseinating recount of the early work on the rice dwarf virus. He has gently shown us that not all ideas are new because forgotten observations in the early literature often pre-date later claims to original thought. Many words have been written on the interaction of viruses and virus strains in plants, and it is 